\title{
The Effect of Arabic Language on EFL University Students' Use of Metaphorical Expressions in Writing
}

\author{
Rasha Hassan Ahmed ${ }^{1}$, Hussein Ali Ahmed ${ }^{2}$ \\ ${ }^{1}$ College of Languages, Nawroz University, Kurdistan Region-Iraq \\ ${ }^{2}$ College of Languages, Nawroz University, Kurdistan Region-Iraq
}

\begin{abstract}
Metaphor is an expression that is used to denote an object, not from a literal meaning, but a similar, figurative meaning. It uses symbols in the place of reality, makes writing more interesting and helps readers understand the ideas the author is trying to convey. Metaphor is a means to think about something, find a new meaning for it, and view it from a different perspective. The current study focuses on the role of EFL university students' native language, namely Arabic in shaping the metaphors used in their writing. It endeavours to find out the types and the frequencies of metaphorical expressions used in essay writing by a sample of EFL university Arab students. As such, the study hypothesizes that EFL university students use of metaphorical expressions in writing is affected by their native language, i.e. Arabic, and that the metaphors used by EFL Arab university students fall within the already known and common domains of metaphor use. To validate the preceding hypotheses, a sample of (21) Arab $3^{\text {rd }}$ year students at the Dept. of English / College of Education/ University of Mosul, Duhok Site during the academic year 2015-2016 was randomly selected and asked to write essays on topics pertinent to their daily life. The results show that there are many types of metaphorical expressions' used by the sample of the study in their writing. This validates the hypotheses set for the current study which state that metaphors are a universal linguistic phenomenon that exists in all languages and are open for use by the speakers of those languages.
\end{abstract}

KEYWORDS : Metaphor, Metaphorical Expressions, Figurative meaning, Literal Meaning, Essay Writing.

\section{INTRODUCTION}

Metaphor exists in all world languages and plays a crucial role in everyday life as it is closely related to culture. Hence, the use of metaphorical expressions has become a universal phenomenon that outlines much creativity on the part of their users, entails the coinage of new words and new grammatical constructions and enriches the vocabulary inventory of a language by ascribing new and metaphorical meaning to old linguistic items. In other words, a language may contain the intended linguistic item, yet the writer seeks for a more beautiful, convenient and effective item to express his massage. As for the problem to be investigated, students' writing performance at university level outlines various defects related to the different aspects

Academic Journal of Nawroz University

(AJNU) Volume 7, No 3 (2018).

Received 10 April 2018;

Regular research paper : Published 20 July 2018

Corresponding author's e-mail : haa_1957@Yahoo.com

Copyright (C2018 Rasha Hassan Ahmed, Hussein Ali

Ahmed.This is an open access article distributed under the

Creative Commons Attribution License. of language. In this respect, a main factor that has been constantly highlighted to negatively affect students' written performance at university level is their native languages at large and the use of some literary tools, including metaphorical expressions in particular. It is said that the latter makes the meaning of the used expressions, phrases and sentences deviate from that intended and leads to not understanding.

The current research hypothesizes the following 1. EFL university students use of metaphorical expressions in writing is affected by their native language, i.e. Arabic.

2. The metaphors used by EFL Arab university students fall within the already known and common domains of metaphor use.

The current research aims at investigating the frequency and types of metaphorical expressions used by EFL Arab students in writing. As such, it is limited to the study of metaphorical expressions in EFL Arab students' written performance in terms of their frequency and types. It is further limited to a sample of (21) Arab 3 $3^{\text {rd }}$ year students at the Dept. of English / College of Education/ University of Mosul, Duhok Site during the academic year 2015-2016. This research is expected to be of value to EFL students through the 
presentation of the role of metaphor as a literary device in the pieces of writing done by them. It may also be beneficial to anyone interested in linguistics at large and in the use of figurative language, i.e. metaphor and metaphorical expressions in particular. The model adopted in this research is based on the main types of metaphors and their use for effective and aesthetic purposes in writing as put forward by Lakoff and Johnson (1980).

\section{Definition of Metaphor}

Metaphor is common to all languages and cultures. Being one of the main types of figures of speech, metaphor is the stylistic feature which almost no utterance can escape. Batchelor (1981 : 334) states that "the word 'metaphor' is derived from the Greek metaphora, which means 'transfer', the composite meta, which means 'transfer, carry over', and pherin which is translated into English as 'to bear', or 'to carry'. Crystal (1992 : 249) defines metaphor as a deviant way of language use which we argue against. Metaphor in the sense of an expression is extended to another concept on the basis of a resemblance. For instance, in 1. Belgian drivers are cowboys. The noun cowboy is not used in its literal sense 'person who tends cattle', but rather invokes the notion 'person who behaves like a cowboy'. It is left up to the hearer to figure out the basis on which the comparison is made (McGregor, 2015 : 132). Black (1993 : 29) visualizes metaphor to have a meaning beyond that of words. For him, metaphor interpretation does not mean comparing the Topic and the Vehicle for the analogies that exist; it rather involves the similarities in existence that lead to new meaning. Finally, metaphor can be defined as a process wherein semantic fields of reference usually overlap. For example, in the sentence :

2. The ship ploughed the water.

The act of farming is paralleled to that of sailing through the use of the verb 'plough' (Allan et al., 2010 : 214).

\section{The Cognitive Feature of Metaphor}

Lakoff and Johnson (1980) make the point that "cognitive linguistics provides a framework within which metaphors can be described and understood, and cognitive linguists claim that metaphor is not merely a figure of speech. It is rather a specific mental and neural mapping that largely influences the way people think, reason and imagine in everyday life". They further think that metaphor is a basic mental operation that enables the writer to understand the world through mapping from known domains to unknown ones, and that some conceptualizations are metaphorically structured in the mind. This forms the starting point for the theory that links between metaphor and thought. Building on this, Cameron (2003:2) states that human thought processes are said to be extremely metaphorical. That is to say, metaphor forms and builds human thoughts. As such, it is claimed that the way individuals construe their experiences with the world is mediated by their bodies nature and that they organize their embodied experience metaphorically.

Accordingly, metaphor is not only seen as figurative use of language, but also as a cognitive strategy that allows people to understand one experiential domain (the 'target domain') in terms of space, and is expressed linguistically via spatial relations. This process, which is called mapping, produces a range of metaphorical expressions in the language that duly retain systematicity in language due to their mental links. Examples are :

3. We've hit a dead-end street.

4. We can't turn back now.

5. Their marriage is on the rocks. (Lakoff $1993: 208-9$ ).

Recently, it has been suggested that some 'primary conceptual metaphors' may be so basic to human experience that they occur in all or most cultural contexts, and may serve as foundational to other metaphors (Grady et al., 1999). For instance, many cultures and languages make a correspondence between size and importance :

6. The big man.

is often the boss or leader. We should note that this only applies to the male of the species.

7. The big woman.

does not seem to work in the same way. The word for big, when translated into other languages, will work as a metaphor (Cameron, $2003: 20$ ).

To conclude, human thought processes are largely metaphorical, and human conceptual system is structured and defined in a metaphorical way. Similarly, metaphor is defined as a cross-domain mapping between source and target domains whose constituent elements are systematically corresponded through mapping. The relationship is in the form of 'TARGET DOMAIN IS SOURCE DOMAIN', both of which are stored together in the mind (Lan and McGregor, 2009 cited in Rasekh and Ghafel, $2011: 212$ ).

IV. The Use of Metaphor (Metaphorical Expressions) as a Linguistic

\section{Device}

Linguists, prior to Lakoff, viewed metaphor as something that lies beyond the borders of normal language, and hence requires special forms of interpretation. Yet Lakoff viewed metaphor, far from its decorative nature to language production, as the essence of all language construction. Put differently, metaphors are used as a means to conceptualize experience. They are unseen, yet they work very deeply within language. So, for example, Lakoff (1993) argues that expressions such as :

8. Time flies. 
9. Time passes.

express the underlying metaphor: Time is a moving object.There is nothing inevitable about this way of perceiving time. Another culture might well conceive of time as stationary, while people do the moving. In this way, Lakoff maintains, a culture's metaphors are an invaluable guide to its values and attitudes (Allan et al., 2010 : 260). There are two viewpoints concerning the use of metaphor in language. First, the classical view, dated back to Aristotle, envisages metaphor as a decorative addition to language. Second, metaphor is viewed as an integral part of everyday language and thought. Undeniably, there is a fine line of distinction between literal and non-literal uses of language. One of the main reasons for this fine distinction is that, as Saeed (2009 : 15) claims, one of the ways languages change over time is by speakers shifting the meanings of words to fit new conditions. One such shift is by metaphorical extension, where some new ideas are depicted in terms of something more familiar. On his part, Al-Jumah (2007: 33) proposes that literal language is objective, whereas figurative language is subjective. Added to that, metaphors can be used as a device for being tactful or to soften a harsh message. For example, instead of saying to a person:

10. You are an unmitigated liar.

One can put it more gently-but just as effectively -in the form of :

11. That is just a cock and bull story.

Similarly one can say :

12. A cobbler should stick to his last.

rather than

13. You are a fool for trying this.

14. Your friend is a slippery customer.

rather than :

15. Your friend tried to cheat me. (Renton, $1990: 27$ ).

Here, metaphors are highlighted as something instilled in human's everyday doings. They are also said to be universal and cultures approach and process metaphors in different ways; a procedure that has culminated in the coinage of the term 'cultural metaphors' to stand for the distinctive tradition closely related to a certain society. Goalty (1997 : 1) states that a language or any of its forms is not existent without metaphor or metaphorical expressions. Metaphor is not limited to language in a rigid way. It runs through all aspects of our daily activities. Of course, language is not an exception. To conclude, Lakoff and Johnson (1980) and
Lakoff (1993) state that metaphorical language based on metaphor as a source is an indispensable part of human life in terms of language, thought and action and is said to be grounded in culture. It plays a major role in people's everyday language use and thinking. Metaphorical expressions have penetrated the various aspects of our life including thought and action (Rasekh and Ghafel, 2011 : 211). A conceptual system is usually developed as it is based on experiences that are acquired through interaction with people and things mainly in the local environment.

\section{Metaphor and Meaning}

The Encyclopedia Americana (1978 : 707) defines metaphor as "a figure of speech presupposing a similarity of two or more things, denotes one of them by terms properly or literally signifying the other as if they are identical". In addition, metaphor is vividly represented by those words which have two meanings when in use. There is first a literal meaning usually referred to as dictionary meaning, and a figurative meaning that is usually intended by the speaker or the writer. According to Palmer (1976 : 103), most examples are words that stand for parts of the body, hand, foot, face, leg, tongue, eye, etc. The preceding set of words applies only to the body, and only some of them can be used with objects in our daily life. Examples are : the clock has no legs, the bed no hands, the chair no tongue, etc.. The use of the last set of examples is referred to as metaphor in both linguistics and literature. Writers in their attempt to enlarge upon the thoughts they bear in mind resort to the use of metaphor and other forms of figurative language to probe meaning and other aspects of the text and to produce more effects on the reader. Carter (1997) cited in Allan et al. (2010: 139) states that meanings are not always overtly present and readers need to seek possible alternative meanings. Also, Allan et al. (2010 : 139) argue that original metaphors and other forms of figurative language (e.g. irony, hyperbole, and understatement) are used to create additional depth of meaning, and the sense of both is unexpectedness and rightness. Lobner (2002 : 51) suggests that the change in meaning due to metaphorical use is not because of lexical ambiguity. He further states that metaphorical shifts occur similarly in other languages, and that the word cowboy is lexically ambiguous between 'cowboy' and 'someone' who is not a cowboy but in certain respects like a cowboy. 
Figure (1) : Meaning Shift according to Metaphorical Use Adopted from Lobner (2002 : 51).

\begin{tabular}{|c|c|c|c|}
\hline $\begin{array}{c}\text { Types of } \\
\text { shift }\end{array}$ & $\begin{array}{c}\text { Lexical } \\
\text { meaning }\end{array}$ & $\begin{array}{c}\text { Shifted } \\
\text { meaning }\end{array}$ & Process \\
\hline \multirow{3}{*}{ metaphor } & \multicolumn{2}{|c|}{ they were China's cowboys } & \\
\cline { 2 - 4 } & $\begin{array}{c}\text { man who herds } \\
\text { cattle }\end{array}$ & $\begin{array}{c}\text { person behaving } \\
\text { like a cowboy }\end{array}$ & $\begin{array}{c}\text { building a new concept in the target } \\
\text { domain by borrowing parts of the } \\
\text { concept in the source domain }\end{array}$ \\
\hline
\end{tabular}

The issue is why speakers use metaphors rather than express themselves literally. Searle (1979) cited in Carpenter (1997 : 29) argues that the key aspect of metaphorical interpretation is the divergence between speaker meaning and literal meaning. He further states that metaphorical meaning is a kind of speaker's meaning that crucially depends on understanding the literal meaning of an utterance. But rather than trying to provide a unified theory of metaphorical interpretation, Searle concludes that the issue of how metaphors function reduces to the issue of how one thing or concept reminds us of another. Thus the reason that some metaphors fail is that some things simply cannot be used to remind us of other things. This intentionally vague "theory" of the interpretation of metaphors does provide an explanation of their utility. A common view is that we depend on metaphors when there is no literal usage that will convey the meaning we intend, or at least not with the same force, economy, or perspicuity. Finally, Searle attempted to expand Grice's approach to metaphors by arguing that, in literal utterance, literal sentence meaning and speaker's utterance meaning are the same whereas they are not identical in metaphoric utterance. Where an utterance is defective of taken literally, the hearer looks for an utterance meaning different from the sentence meaning by virtue of the notion of 'similarity'. When ' $S$ is $\mathrm{P}^{\prime}$ is stated and assigning the literal value of $\mathrm{P}$ results in a defective interpretation, the hearer searches for some other possible value $R$ similar to the literal value of $P$.

\section{Metaphor in Arabic}

Metaphor has been used excitedly by the Arab speakers in different ages and places (cities and suburbs). By virtue of those talented users', Arabic language has achieved the fullest wonderfulness in Pre-Islamic and Islamic eras (Al-Dimishqi, 1996). Moreover, sophisticated poets, experts in rhetoric, including writers and orators highlighted a creative and a wonderful use of metaphor that can only be understood by the smart and the shrewd and those who are skilled in the indirect use of an expression. However, metaphor is not to be considered as punning in speech, as arbitrary moves of using a word or an expression ascribed to a meaning, or using a word or an expression in the place of others that are specified to another meaning. Instead, it is a mental activity that communicates meaning, linked by bonds and intellectual relationships through which the speaker can use the expression in conveying a meaning to denote another. The hearer, on his part, understands the utterance according to the context wherein it is produced (Al-Dimishqi, 1996). Metaphor is defined as the articulation that is used in contexts that are not put for it. It should properly be proved within the general linguistic and intellectual proceedings associated with a context. So without context, the utterance does not refer to the metaphorical meaning.

If we say

24. الوادي يجري the valley flows,

we have ascribed 'running' to the valley, as the valley does not stream, yet it is the water that streams. This is called metaphorical attribution and it is a kind of mental metaphor. According to Al-Mut?ani (1995), metaphor in speech falls into two main categories, namely linguistic metaphor and mental metaphor. Linguistic metaphor means that the utterance can be used in contexts other than their linguistic meaning. For example, when the word "lion" is used to denote a "brave man" :

25. Mohammad is like the lion

or using the expression :

أراك تمد خطوة الى ألأمام و أخرى الى الخنف .26 ألف

I see you move a step forward and get the other back. with regard to :

27. أراك مترددا I see you hesitant.

Accordingly, mental metaphor can be said to outlines the freedom of thought by stressing one of the meanings denoted by a fact or a metaphor. This is on one hand. On the other hand, Al-Dimishqi (1996) states that metaphor in Arabic is classified into four main categories :

a. Single (Simple) Metaphor : It is a single utterance in which it is used.

Examples are :

28. He is like the lion.

29. He has the upper hand. 
"lion" and "hand" in relation to a "brave man and "power" respectively.

b. Compound Metaphor: It is a compound utterance that is used in the meaning other than that it is used in the real sense. Consider this example :

30. أراك مترددا I see you hesitant.

c. Predicative Metaphor : It is a mental metaphor to which a verb is ascribed to another context. An example is :

31. The valley flows.

d. Extension-Based Metaphor : It is based on language without any restrictions. Such extension appeals to various facets, which is not subject to regulations. Examples are addition and deletion in speech or applying the past to the future.

\section{B. The Practical Part}

\section{Description of the Test}

The test for the current research required the writing on-spot essays of at least five paragraphs (one introductory paragraph, three body paragraphs and one conclusion paragraph) by a group of Arab EFL university students on topics that were interesting to them.

\section{Subjects of the Test}

21 male and female $3^{\text {rd }}$ year students at the Department of English, College of Education / University of Mosul,
Duhok Site whose native language is Arabic represented the sample of the research.

IX. The Validity and Reliability of the Test

According to Lado (1961:321), test validity means that the test is relevant to what it claims to measure or what it purports to measure. It aims to improve and qualify the quality of the test questions or tasks before its actual administration. While reliability, as Birolini (2014: 299) reports, is the degree of accuracy with a given test or a set of scores that measures whatever is measuring. It is mainly concerned with consistency and fairness of scores resulting from administration of a particular examination. In our case no panel of juries was required to prove the validity of the test in the first place, and also no pilot study was required to prove the test reliability since the respondents were asked to write an essay on (Experiences in Life : Family as a Main Source) taking into considerations the required principles and regulations.

\section{Data Analysis and Discussion of Results}

Based on Lakoff and Johnson (1980) as the Adopted Model of the present research, data analysis will be based on the use of metaphorical expressions in three domains, namely ontological, structural, and orientation. But first, all metaphorical expressions used by the sample of students are listed below :

\begin{tabular}{|l|}
\hline \multicolumn{1}{|c|}{ Metaphors Used by Arab Students } \\
\hline - Her parents had removed to live in a distant places. \\
\hline - Life is money. \\
\hline - Money is the only language he could understand. \\
\hline - The efforts had failed. \\
\hline - Spend more time together. \\
\hline - The society oppresses woman. \\
\hline - Society makes her a weak. \\
\hline - She cannot defend her right. \\
\hline - My Father is the great pillar. \\
\hline - The words and pictures fly very fast from my brain. \\
\hline - I could handily catch one or two of that words and pictures. \\
\hline - Before my imagination jumps. \\
\hline - Mother is the one of Kindness angle. \\
\hline - Mother gathers all her sons under her warm wings. \\
\hline - My parents another greatest gift. \\
\hline - Parents are diving gifts on earth \\
\hline - Parents are the source of our life. \\
\hline - Parents are a candle that lights our house. \\
\hline - Mother is a bird of paradise. \\
\hline - My Father is mainstay of the house. \\
\hline -The paradise under the Mother's feet. \\
\hline -The earth is a friend with moon. \\
\hline -The dog is a friend. \\
\hline -The woman accepts to be the next number in her husband's life. \\
\hline - Reading is the food of Soul. \\
\hline
\end{tabular}




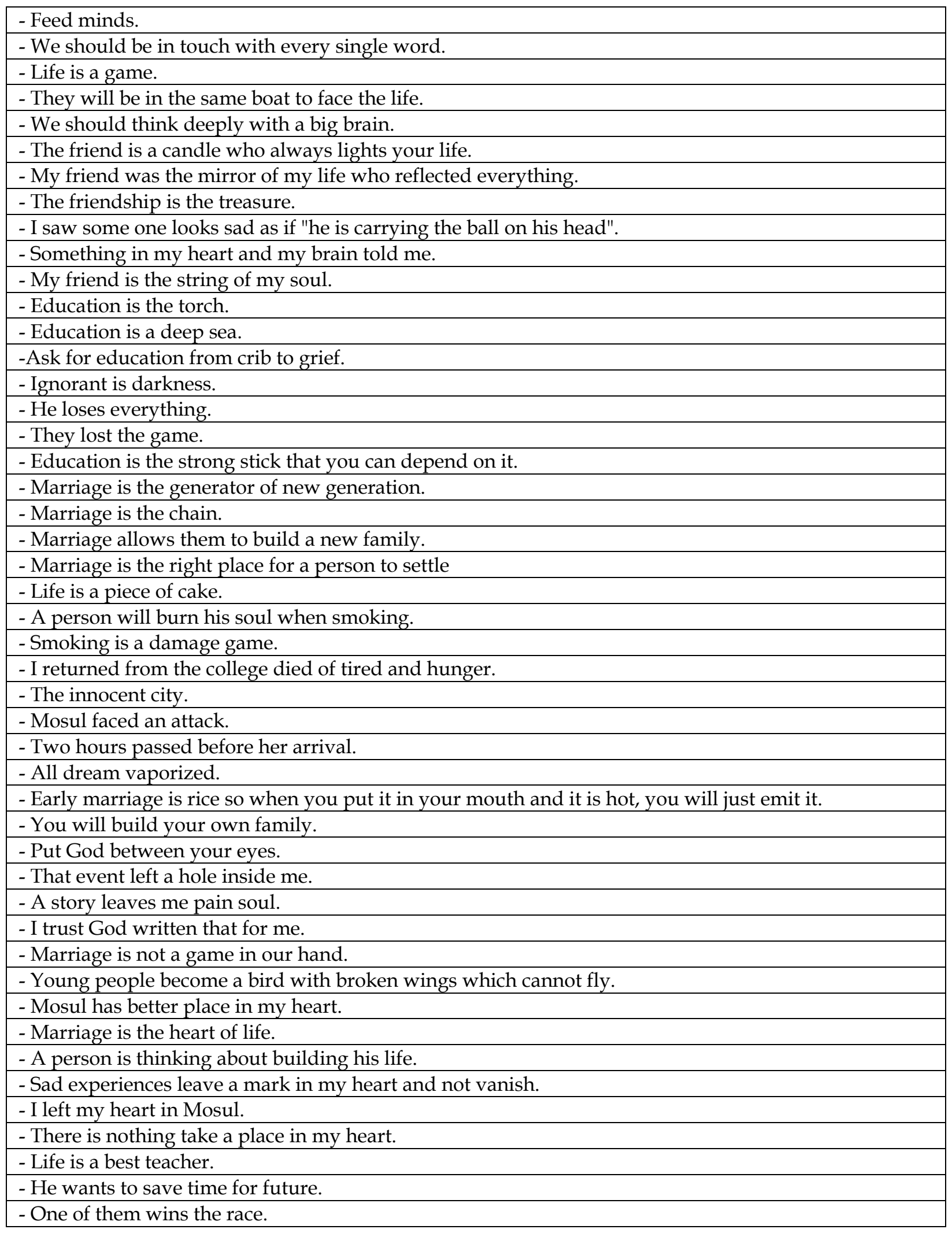

It is evident that EFL students made use of many metaphorical expressions which outline interference by their native language, i.e. Arabic. Examples are : 32. The emotion and passion can build family.

33. Marriage will help to build family.
34. Marriage allows them to build a new family. In the preceding examples, the act or the practice of constructing houses, office buildings, etc. is clearly reflected in such a way that outlines the influence of participants' native languages on their writing. 
Accordingly, the first hypothesis which states: "EFL university students use of metaphorical expressions in writing is affected by their native language, i.e. Arabic" is accepted. As for the second hypothesis which states : "The metaphors used by EFL Arab university students are variedly distributed among the already known and common domains of metaphor use", it is worthy to note that metaphorical expressions fall into six domains, viz. physical body, orientation metaphors, idioms, structural metaphors (Time as Resource), Game and War and ontological metaphors (personification). Undeniably, difficulty is experienced in pinpointing and identifying the precise expressions equivalent to the English ones that fall within the preceding six domains. As such, for the sake of making the metaphorical expressions easy and clear, the vague ones will be set aside and focus will be on those which clearly belong to the domains under discussion. Added to that, for more accurate presentation and discussion, the frequency related to each one of the six studied domains will be presented separately. Table (1) demonstrates such a use :

Table (1) : Metaphor Domains Used in the Sample's Writing

\begin{tabular}{|c|c|}
\hline Domain & $\begin{array}{c}\text { Total Number of Metaphors } \\
\text { Used }\end{array}$ \\
\hline 1. Orientation Metaphor & 3 \\
\hline 2. Physical body & 10 \\
\hline $\begin{array}{c}\text { 3. Structural Metaphor (Time as } \\
\text { resources) }\end{array}$ & 2 \\
\hline $\begin{array}{c}\text { 4. Ontological Metaphor } \\
\text { (personification) }\end{array}$ & 16 \\
\hline 5. Idioms & 10 \\
\hline 6. War/ Game & 12 \\
\hline TOTAL & 53 \\
\hline
\end{tabular}

It is evident that the highest frequency metaphors used is in the domain of ontological metaphor or personification (16). Also very near frequencies appear in the War/Game, Physical Body, and Idioms $(12,10$, 10 consecutively). The least frequencies ( 2 and 3 ) are for orientation and structural metaphors respectively. For better understanding and familiarity with the metaphorical expression used in each domain, the expressions relevant to each domain will be presented in separate figures after a cursory review of each domain and as follows :

\section{a. Orientation Metaphors}

Orientation metaphors give concepts spatial orientation by associating an abstract knowledge area with some aspect of experiential knowledge. Below are the metaphorical expressions used by the sample of the study :

1.The paradise under the mother's feet.

2. We should think deeply with a big brain.

3. Education is a deep sea.

b. Physical Body

Physical body constitutes the second domain which subsumes the metaphors that the students have used in their essays. Following are the metaphorical expressions related to the physical body metaphors used by the sample of students :

1. The paradise under the mother's feet.

2. Feed minds "Reading"

3. We should think deeply with a big brain.

4. I saw some one looks sad as if "he is carrying the ball on his head".

5. Something in my heart and my brain told me.

6. Put God between your eyes.

7. Marriage is not a game in our hand.

8. Mosul has better place in my heart.

9. Sad experiences leave a mark in my heart and not vanish.

Table (2) illustrates the frequency of the use of metaphorical expressions for each body part. It is clear that the part "heart" is the most frequently used body part (10 times use) in terms of the metaphorical expressions relevant to it.

Table (2) : Frequency of the Body Parts Metaphors Used by the Sample of Students

\begin{tabular}{|c|c|c|c|c|c|c|c|c|c|}
\hline hand & eyes & brain & heart & feet & Head & mind & liver & face & Total \\
\hline 2 & 1 & 0 & 6 & 0 & 0 & 0 & 1 & 1 & 11 \\
\hline 1 & 1 & 2 & 3 & 1 & 1 & 1 & 0 & 0 & 10 \\
\hline
\end{tabular}




\section{c. Structural Metaphors (Time as Resource)}

In the conceptual metaphor TIME AS RESOURCE, TIME is considered as a valuable commodity, a limited resource. TIME, allows us to talk about budgeting time, saving time, using time profitably or losing time. These expressions are called structural metaphors. The sample of students has used words like, "spend", "waste" and "save" as follows :

a. They spend more time together.

b. He wants to save time for future.

\section{d. Ontological Metaphor (Personification)}

It is evident that the sample of students has used a noticeable number of ontological metaphorical expressions. Students have used abstract concepts as physical objects such as "society loves boys", "the words and pictures fly" and "book is a child". In these expressions, it is clear that the subjects deal with an abstract concept as it is a physical object :

1 . The Society oppresses woman.

2. Society makes her a weak person.

3. The words and pictures fly very fast in my brain.

4. Before my imagination jumps.

5 . The earth is friend with moon.

6 . Reading is the food of soul.

7. Feed minds.

8. Marriage is the generator of new generation.

9. Marriage allows them to build a new family.

10. The innocent city.

11. Mosul faced an attack.

12. Two hours passed.

13. That event left a hole inside me.

14. A story leaves me pain soul.

15. Sad experiences leave a mark in my heart not vanish.

16. Life is a best teacher.

\section{e. Idioms}

Idiomatic phrases are represented by the use of several metaphorical expressions like : 'reading is the food of the soul,' education is light' and 'the ship sailed in other side of my dream". A limited number of specific idioms have appeared in the languages under study. Furthermore, the effect of the students' native language and culture is evident in the use of metaphorical expressions relevant to this domain. An example is : "The man is mercy even he is a coal" because in the eastern society people use this expression as triumph for a man :

1. Mother gathers all her sons under her warm wings.

2. Mother is a bird of paradise.

3. The paradise under the mother's feet.

4. Reading is the food of soul.

5. They will be in the same boat to face the life.

6. "Ask for education from crib to grief".

7. Education is light.

8. Ignorant is darkness.
9. A bird with broken wings which cannot fly.

10. Life is a best teacher.

\section{f. Game/War}

This domain, through its frequencies, has come close to the ontological domain or personification. In other words, these metaphorical expressions are among the most widely used ones and can be seen in the words 'game,' 'jump,' 'lose,' 'play,' 'win,' fight,' 'defense' and 'occupation,' all of which describe how 'players' or 'opponents' behave in the field, and all of which correspond to possible English forms. In the light of the permanent unstable situation in the Middle East, 'terrorism' has become a prevalent popular worldwide phenomenon. So most people use some particular war metaphors in their day-to-day speech :

1. Life is game.

2. Smoking is a damage game.

3. Marriage is not a game in our hand.

4. The woman accepts to be the next number in her husband's life.

5. Her efforts had failed.

6. Before my imagination jumps.

7. They lost the game.

8. One of them wins the race.

9. He loses everything.

10 She cannot defend her right.

11. They will be in the same boat to face the life.

12. Mosul faced an attack.

In the light of what has been so far stated and discussed pertaining to the domains of the use of metaphorical expressions, Hypothesis no. 2 is also accepted.

\section{Conclusions}

In the light of the theoretical presentation of the related literature and data analysis, the following conclusions have been arrived at :

1. Metaphorical language forms an integral part of human life in terms of language, thought and action. It has great importance in the field of writing because writers use metaphor to convey their feelings.

2. The native speakers of different languages and of different cultures adopt different ways of handling and using metaphors.

3. The most noticeable set of metaphorical expressions include words that stand for parts of the body, namely hand, foot, face, leg, tongue, eye, etc.

4. There are different types of metaphor but most of them utilize the strategy of conveying something less known through the use of something more familiar and more concrete.

5. Cognitive linguistics has shifted focus of attention from metaphor in language to metaphor in mind, or 'conceptual metaphor'. As such, metaphor must be investigated in both language and mind.

6. Conceptual metaphors typically employ a more abstract concept as target and a more concrete or 
physical concept as their source.

7. Metaphors abound in EFL students' writing due to the influence of their native language. In fact, typologies of metaphor abound but we have tried to talk about some distinctive types because an active metaphor today will probably be a dead one in the future.

8. There are many types of metaphorical expressions' usage that appeared in Arab students' writing.

9. The findings that validate the null hypotheses of the current research approve that metaphors are a universal linguistic phenomenon that exists in all languages and are open for use by the speakers of those languages.

\section{Recommendations}

1. Since writing in a foreign language is often considered the most difficult skill in comparison to the other three language skills, namely, listening, speaking, reading, and since there are many factors that may hinder students' attempts to convey their real feelings from their native language into English, this skill should be heavily heeded by university instructors of composition and essay writing.

2. Since EFL students, who speak different languages, usually search for the most effective means to express themselves in a better way with the least effort and time required, instructors of writing at large, and those of essay writing in particular have to teach them the strategies of good writing in general and those on the use of metaphorical language in particular.

3 . Based on 1. above, distinguishing literal language from metaphorical language should be a prime objective behind the teaching of writing to EFL university students.

\section{References}

1. Al-Jumah, F. H. (2007).A Comparative Study of Metaphor in Arabic and English General Business Writing with Teaching Implications. Pennsylvania : University of Pennsylvania.

2. Allan K.; Bradshaw J.; Finch G.; Burridge K.and Heydon G. (2010).The English Language and Linguistics Companion. UK : Palgrave.

3. Batchelor, H. (1981). "Metaphor in Academic American Encyclopedia", vol. 13, New Jersey : Arete Publishing Company.

4. Birolini, A. (2014). Reliability Engineering : Theory and Practice. Berlin : Springer.

5. Black, M. (1993)."More about metaphor". In A. Ortony (Ed.),Metaphor and thought). Cambridge : Cambridge University Press, pp. 19-41.

6. Cameron, L. (2003).Metaphor in Educational Discourse. London : Continuum.

7. Carpenter, B. (1997). Type-Logical Semantics. England
: A Bradford Book, The MIT Press.

8. Crystal, D. (1992). A Dictionary of Linguistics and Phonetics. 2nd edition. New York : Blackwell Publishers.

9. Goalty, A.(1997).The Language of Metaphors. New York : Routledge.

10. Grady, J.; Oakley T. and Coulson S. (1999). " Blending and metaphor." In Gibbs and Steen (eds.) (1999) Metaphor in cognitive linguistics. Amsterdam : John Benjamins, p.79-100

11. Grice, P. (1990). Studies in the way of words. Harvard : Harvard University Press.

12. Lado, R. (1961). Language Testing : The Construction and Use of Foreign Language tests. London : Longman Group Ltd.

13. Lakoff, G. (1993). The Contemporary Theory of Metaphor. In Ortony, A (Ed), Metaphor and Thought. Cambridge : Cambridge University Press, pp.202-251.

14. Lakoff, G. and Johnson, M. (1980). Metaphors we live by. Chicago : The University of Chicago Press. In Cognitive Science 4, 195-208 : doi : 10. 1207/ s 15516709 Cog 0402_4. Article first publish online : 11 Feb 2010.

15. Lobner, S. (2002). Understanding Semantics. UK : Hodder Education and Hachette UK Company.

16. McGregor, W. B. (2015). Linguistics : An Introduction. London, New York, Bloomsbury Publishing Plc.

17. Palmer, F. R. (1976). Semantics. Cambridge : Cambridge University Press.

18. Rasekh, A. E. and Ghafel, B. (2011) Basic Colors and Their Metaphorical Expressions in English and Persian : Lakoff's Conceptual Metaphor Theory in Focus. 1st International Conference on Foreign Language Teaching and Applied Linguistics May 5-7 2011 Sarajevo.

19. Renton, N. E. (1990). Metaphorically Speaking. New York : Time Warner Company.

20. The Encyclopedia Americana (1978). New York : Penguin Books.

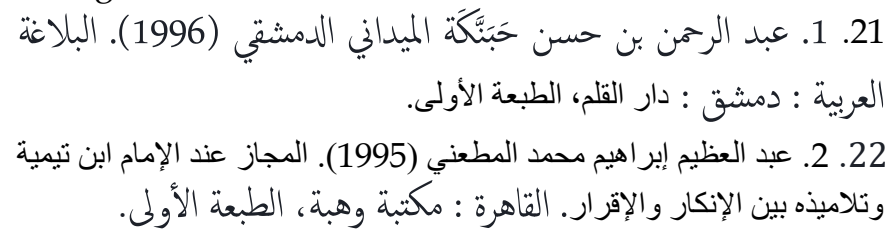

